\title{
Minimalism and Phenomenological Evidence
}

\author{
PATRICIA MARECHAL
}

\begin{abstract}
It has been recently argued that the phenomenology of semantic perception casts doubts on Grice's theory of meaning. I defend the psychological and theoretical plausibility of a form of Gricean minimalism, by setting new boundaries to the semantic-pragmatic distinction. This strategy consists in abandoning the entailment from what is said to what is meant, and advancing a conception of the semantic notion of what is said that departs from speaker-hearers' intuitions. This proposal has important consequences both concerning the evidence that should be used by philosophers of language when evaluating semantic theories, and the way we should carve up linguistic processing.
\end{abstract}

Keywords: Semantics; pragmatics; minimalism; semantic perception; linguistic processing.

When we attend to the phenomenological experience of public language it becomes evident that (i) on many occasions our experience of what is said by an utterance does not correspond with the perceived structural elements of an expression, i.e. our experience of what is said goes beyond what is syntactically encoded in the utterance; and that (ii) the meaning of expressions is experienced as a free-standing property independent of the speaker's intentions. ${ }^{1}$ Speaker-hearers might, in certain circumstances, become aware of the contributions of intentions to the meaning of utterances, but our ordinary communicative exchanges involve this peculiar form of "semantic blindness" (Azzouni 2013, p.56).

The phenomenology of semantic perception casts doubts on Grice's theory of meaning. On Grice's view, what is meant by an utterance is a form of non-natural meaning (Grice 1957). According to Grice, non-natural meaning, or speaker's meaning, is mediated by the recognition of intentions between a speaker and an audience, based on what is said by the speaker, how he said it, and what is implicated in the act of utterance. Grice's proposal relies on speaker-hearers' being able to access what is said by an expression. It is the consciously accessible character of what is said that guarantees that the audience will be able to make inferences about what the speaker means.

In order to save Grice from the counterevidence coming from the phenomenology, one could abandon the requirement of conscious accessibility of what is said. Several scholars that defend minimalist notions of what is said have followed this strategy. In a nutshell, minimalism claims that "[t] he semantic content of a sentence $S$ is the content that all utterances of $S$ share' (Cappelen and Lepore 2005, p.143). Semantic

Principia 21(1): 141-153 (2017).

Published by NEL — Epistemology and Logic Research Group, Federal University of Santa Catarina (UFSC), Brazil. 
content is maximally free from contextual effects, and "context is semantically relevant only when introduced by a standardly context-sensitive syntactic element, e.g. indexicals, demonstratives, tense markers" (Borg 2004). A consequence of this view is that what an utterance says differs from what it intuitively means.

Salmon (1986), Manuel García Carpintero (2001), Soames (2002), Borg (2004), and Cappelen and Lepore (2005) have defended versions of minimalism that go from moderate to radical, according to the notion of context adopted and its role in the determination of semantic content. Prominently, Kent $\mathrm{Bach}^{2}$ has advanced a moderate version of minimalism. Bach expands Grice's original bipartite distinction between what is said and what is implicated to a tripartite distinction that includes a middleground notion that he calls "impliciture". By adding this intermediate layer, he protects what is said from pragmatic intrusion. On his view, what is said is a semantic structure that does not correspond with what is (normally) intuitively accessed by speaker-hearers. On the other hand, implicitures are a pragmatic expansion of the semantic content and they are intuitively accessible.

In what follows, I will present Grice's notion of what is said, as initially elaborated by Grice, and I will explore the problems this notion entails. Then, I will introduce Bach's proposal, and I will argue that his version of minimalism can respond to the two challenges posed by the phenomenological experience, while remaining, at the same time, theoretically and empirically plausible. I am ultimately interested in defending the psychological and theoretical plausibility of a form of minimalism, and its capacity to respond to phenomenological objections. Thus, I will offer answers to objections to Bach's account. However, I am not committed to the view that Bach's presentation is, as it stands, complete and accurate. Finally, I will go back to the phenomenology of our experience of utterances and I will argue that research on semantics should not rely directly on speaker-hearers' intuitions.

\section{I}

One of the most important contributions of Grice's theory of meaning is the distinction between what is said and what is implicated. According to Grice, what is said is the result of three factors: conventional meaning, contextual elements that determine the referents of indexicals and disambiguate expressions, and speaker's intentions (in the sense that what is said must be meant by the speaker). It is important to notice that Grice relies on our "intuitive understanding of the meaning of say" (Grice 1989, pp.24-25). This means, on the one hand, that this notion is supposed to refer to the ordinary, everyday sense of 'what is stated' (Levinson 2000, p.194) and, on the other hand, that speaker-hearers are aware of what is said and perform inferences on the basis of its semantic properties. In contrast, the notion of implicature is introduced to 
account for cases in which what the speaker actually says is different from what the speaker means. Most importantly, Grice's distinction between what is said and what is implicated is supposed to trace a boundary between semantics and pragmatics.

Grice's characterization of the notion of what is said implies that $U$ (the utterer) said that $p$, if and only if: " $U$ did something $x$

(1) by which $U$ meant $p$

(2) which is an occurrence of an utterance type $S$ (sentence) such that

(3) $S$ means ' $p$ '

(4) $S$ consists of a sequence of elements (such as words) ordered in a way licensed by a system of rules (syntactical rules)

(5) $S$ means ' $p$ ' in virtue of the particular meanings of the elements of $S$, their order, and their syntactical character."

According to Grice, what is said corresponds to "the elements of the sentence, their order, and their syntactic character" (1989, p.87). This implies that, if there are elements in the content that the speaker is trying to convey that do not correspond to elements of the sentence being uttered, these are not a part of what is said. But, although at first glance Grice's notion of what is said seems to correspond to the context-invariant content of utterances, he explicitly says that it includes indexicality and disambiguation. Therefore, Grice's notion of what is said includes minimal contextual elements.

As mentioned in the introduction, two different objections based on the experience of speaker-hearers can be raised against Grice's notion of what is said. The first is that, given the syntactic characterization of point (4), even if indexical references are assigned and ambiguities are resolved, many sentences are semantically incomplete. In other words, ordinary speaker-hearers' experiences of what is said often do not correspond to their perception of the structural elements of the uttered expression. Let us consider as an example the following sentence:

1. I've had a shower.

Sentence 1 expresses the proposition that the speaker has had a shower before the time of utterance, which would be true if the speaker has had a shower only once in her life. However, it is clear that this is not what the speaker means; she means something more specific, namely that she has had a shower that day. In other words, sentence 1 seems to say more than what its syntactical constituents indicate; it seems to express something like "I've had a shower [today]". This and other examples cast doubts over the exhaustive character of Grice's bipartite analysis of utterer's meaning in terms of what is said and what is implicated.

Principia 21(1): 141-153 (2017). 
A second critique from the phenomenology of the experience of linguistic expressions is that, according to Grice, what is said is determined by the speaker's intentions. This is so because what is said and what is implicated are varieties of non-natural meaning and, in short, non-natural meaning involves the recognition of communicative intentions. But the problem is that "the ordinary speaker-hearer doesn't, even in ordinary circumstances, experience the meaning of an expression uttered as part of what the speaker meant" (Azzouni 2013, p.118). According to Azzouni, the phenomenology of linguistic experience suggests that speaker-hearers perceive meaning as a free-standing property that is not due to the intentions of speakers. Meaning is not consciously experienced as depending on the speaker's intentions: we do not seem to need to recognize intentions in order to have a grasp of what is barely said by an utterance.

\section{II}

In order to respond to the first objection, Kent Bach has argued that the Gricean distinction between what is said and what is implicated is not exhaustive. This has important consequences since, according to Bach, we should not ipso facto assume that if a conveyed proposition is not an implicature it must be immediately identified with what is said. Bach introduces the notion of impliciture to account for cases like:

2. Jack is ready.

Sentences like these express incomplete sentences - in Bach's terms, propositional radicals $^{3}$ - thus they cannot be evaluated truth-conditionally. But, undeniably, the speaker meant something complete and truth-evaluable when he uttered 2; what the speaker actually meant is:

2'. Jack is ready [to leave].

The words in brackets are not a part of what the speaker said, but they are a part of what the speaker meant, and they contribute to what is communicated. However, the expanded proposition is not an implicature, because the words in brackets contribute to the truth-content of the uttered expression. Therefore, Bach concludes that there is an intermediate layer between what is said and what is implicated. The vehicle of this enriched or expanded proposition is an impliciture, a term coined by Bach to express that this notion captures what is implicit in what is said. As Bach points out, "[i]mplicitures go beyond what is said, but unlike implicatures, which are additional propositions external to what is said, implicitures are built out of what is said" (1994, p.141). This level is also frequently characterized by Bach as "what is stated". One of the marks that distinguishes implicitures from what is said is that the former can be

Principia 21(1): 141-153 (2017). 
felicitously cancelled. Going back to our example, it is possible to state that "Jack is ready but not to leave, to go to bed".

Echoing the distinction introduced by Austin (1962) between locutionary and illocutionary acts, what is said, according to Bach, corresponds to the locutionary act; i.e., what is said is certain noises that conform to a grammar and have a more or less definite sense and reference. Bach thinks, with Grice, that what is said is closely correlated with the meaning of the constituents of a sentence and how they are syntactically arranged. But, unlike Grice, he does not think that there is an entailment from what is said to what is meant. Not only this proposal explains literal assertions, it also accounts for cases when we do not speak literally: when we speak metaphorically, we are saying — for example, when we express metaphors - we are saying something that is different from what we mean to say (a phenomenon that Grice explained by the awkward distinction between 'saying' and 'making as if to say'). Bach's proposal also explains verbal mistakes such as slips of the tongue and utterances produced with understanding but that do not mean anything, such as recitations, sentences pronounced when someone is learning a language, or decontextualized translations from a foreign language.

As explained before, Bach imposes a strong syntactic correlation, constituent by constituent, between what is said and the linguistic expression uttered in a context, i.e. a sentence token. He claims that what is said consists in nothing more than the sentence expressed "with respect to the context of utterance". He follows Grice's proposal that there is a sense in which context is relevant to semantics, insofar as the interpretation of indexical items is required. Thus, he introduces a notion of "restricted" or "narrow" context that differs from the broad context involved in pragmatic inferences. This narrow context consists of a small, well-defined set of objective parameters that include the speaker, the addressee, and the time, day, and place of utterance (Bach 2001; Kaplan 1989). What makes certain cases of reference assignment semantic is that they do not involve the speaker's intentions.

How does Bach's proposal respond to the two problems faced by Grice that I presented in the last section? The first challenge does not require much elaboration. Grice imposes strong syntactic constraints on what is said, and he suggests that we are aware of what is said. But, as the examples above showed us, what we perceive as what is said goes beyond these syntactic constraints: what we hear when someone utters "I have taken a shower" differs from what the utterance says. Here is where the notion of impliciture becomes relevant. Implicitures are an expansion of the purely semantic what is said. The pragmatic processes of expansion add extra conceptual content to the sentence or propositional radical that constitutes what is said. In the case of sentence 1 , the expanded proposition would be the one expressed by "I have taken a shower [today]". This enriched proposition is what the speaker actually means, and what the hearer actually perceives. 
The second challenge from the phenomenological experience was that, intuitively, what is said is not experienced as depending on the speaker's intentions: we do not consciously engage in a process of recognition of intentions in order to infer what is said by an utterance, or what an expression means. According to Bach, since saying something does not entail meaning it, what is said does not depend on someone having a communicative intention; i.e. the speaker's intentions do not contribute to the determination of what is said. In other words, Bach's notion of what is said is a semantic notion: the content of what is said is information encoded in what is uttered; it is not information that arises from an act of utterance. Bach's proposal is that what is said is determined linguistically and is not permeable to communicative intentions. Most importantly, the speaker's intentions only play a role in what is meant by a speaker. As such, there is a clear gap between linguistic meaning and speaker's meaning; and, moreover, what is said is not usually a part of our conscious experience. This strategy allows Bach to respond to the mentioned objection. On Bach's view, what is said does not depend on the recognition of intentions, since "[t]here is no such constraint on contextual information of the semantic kind, which has its effect independently of the speaker's communicative intention and the hearer's recognition of that intention" (2001, p.22).

However, even if, according to Bach, what is said does not depend on the recognition of intentions, what is meant in a communicative situation does. Thus, the phenomenological objection that says that ordinary hearers do not have conscious experience of the speaker's intentions determining the meaning of an utterance still stands. The phenomenology of linguistic experience suggests that speaker-hearers perceive meaning as a free-standing property that is not due to the intentions of speakers in any way (Azzouni 2013). In other words, the effect of the speaker's intentions on the meaning of utterances is not perceived as having the causal role that they, in fact, may have. Can Bach answer this objection? I believe he can.

The meaning of an utterance can be determined by the speaker's intentions in the sense of being constituted by them or in the sense of being consciously established on the basis of (the hearer's recognition of) those intentions. The latter option involves conscious epistemic accessibility by the hearer. My contention is that Bach is only committed to the claim that the speaker's intentions play a role in the determination of meaning in the former sense, i.e. meaning is constituted by speaker's intentions, but it does not require that the hearer be aware of the constitutive role played by those intentions. Thus, meaning does rely psychologically on the recognition of communicative intentions, but this recognition does not need to be understood in a conscious way: it can be understood as subpersonal expectations and subliminal recognitions.

This may sound problematic to many. The usual way of interpreting the "recognition of intentions" involved in speaker's meaning is that it entails conscious accessibility of the inferential processes and the information on the basis of which those 
inferences are worked out. Recanati's distinction between primary and secondary pragmatic processes illustrates this. According to Recanati:

Secondary pragmatic processes are 'post-propositional. They cannot take place unless some proposition $p$ is considered as having been expressed, for they proceed by inferentially deriving some further proposition $q$ (the implicature) from the fact that $p$ has been expressed. In contrast, primary pragmatic processes are 'pre-propositional: they do not presuppose the prior identification of some proposition serving as input to the process. Another difference is the fact that secondary pragmatic processes are conscious in the sense that normal interpreters are aware both of what is said and of what is implied and are capable of working out the inferential connection between them. Primary pragmatic processes are not conscious in that sense (2004, p. 23, my italics).

Recanati claims that interpreters are not only aware of what is inferred and on the basis of what it is inferred, they are also conscious of the inferential connection between the two.

However, the conscious requirement for secondary pragmatic processes is unwarranted: there is nothing psychologically odd about unconscious rational inferences, and Gricean inferences are perfectly good candidates to be a kind of subpersonal inference. Moreover, why is conscious accessibility needed in the case of secondary inferential processes (in terms of Bach's terminology, the processes that go from implicitures to implicatures), but not in primary processes (the processes that give rise to Bach's semantic what is said)? García Carpintero exposes how Recanati's view does, after all, rely on the possibility of subpersonal inferences:

This is compatible with Recanati's views on primary pragmatic processes: the actual processes involved in giving rise, in real time, to what he counts as what is said can be characterized as inferences, but they are merely inferences at the subpersonal level, in which "what is literally expressed" plays no role as a premise in a conscious inference. The present point is that the same applies to secondary processes in actual cases (2006, p.60).

If we accept subpersonal inferences in primary processes, we have no reason to rule out subpersonal inferences at the level of secondary processes.

My proposal is that Gricean pragmatic inferences can be interpreted, plausibly, as an exercise of mind-reading abilities. The attributions of intentions that give rise to speaker's meaning consist in applying theory of mind abilities to the domain of communication (Sperber and Wilson 2002). It has been well established in the mindreading literature that the inferential processes underlying the attribution of intentions are, for the most part, automatic and unconscious (although some of them can be consciously reconstructed by the agent when she deliberately focuses on an event)

Principia 21(1): 141-153 (2017). 
and they are possibly subserved by a series of domain-specific sub-systems or modules (Wilson and Sperber 1986; Leslie and Thaiss 1992; Scholl and Leslie 1999). ${ }^{4}$

But, even if we accept that the inferences involved in communication can be subpersonal, it seems odd to claim that one would be able to infer implicitures ("what is stated") from what is said without being able to consciously distinguish implicitures from what is said. In other words, inferring implicitures from what is said seems to require distinguishing what is said from what is stated. Thus, we should be conscious of what is said and the impliciture inferred if what is said is going to play any role in our inferences, even if we are not conscious of the inferential processes per se. My response to this is that if we give up the idea that the inferential processes in communication are conscious, we can give up the idea that people must, in all cases, consciously distinguish what is said from what is stated, and what is stated from what is implied. And this is exactly what happens: people have to be appropriately cued, asked, and instructed to make systematic distinctions between what an expression minimally says, what it states, what it means, etc. People might be able to become conscious of these structures with the proper training, and this is likely to vary according to the person and the circumstances. Most importantly, this entails that the conscious opinions and intuitions of ordinary speakers will not be authoritative for our semantic theories.

Still, a worry remains: by dropping the conscious accessibility of what is said and the inferential processes involved in communication, Bach's notion could become an abstract theoretical construct with no psychological reality or empirical role. This has been an important objection advanced by Recanati (2001), according to whom, if the hearer cannot identify the minimal semantic what is said before inferring the speaker's intention and enriching it with pragmatic elements, then the notion is a mere abstraction that plays no theoretical or psychological role:

[T] he minimal proposition does not correspond to an aspect of what the speaker asserts and cannot be abstracted from it [... The minimal proposition is a hybrid which goes beyond what is determined by the rules of the language yet has no psychological reality and need not be entertained or represented at any point in the process of understanding the utterance (Recanati 2004, p.64).

Bach's response to this objection is that the fact that sometimes what is said cannot be intuitively accessed by the speaker does not show that it is merely an abstraction or that it does not play an empirical and theoretical role in the actual understanding of utterances. As Azzouni (2013) points out, Recanati's objection to Bach's notion cannot be that the notion does not have an empirical role just based on the idea that subjects cannot access it consciously. Bach's what is said can have psychological reality and play an important role in our communicative practices even if it is not 
accessed. Most importantly, Bach's notion of what is said is a minimal semantic constituent of speaker's utterances. The semantically encoded information of what is said contributes to the understanding of what is communicated and to the truth-content of the utterance. The fact that speaker-hearers do not usually have intuitive access to that structure does not mean that the minimal what is said is not potentially consciously accessible or that it is not directly available in many ordinary circumstances. Although many scholars have denied that literal meaning can be consciously accessible to language users (Carston 2002; Recanati 2004) this has been recently challenged (Hansen 2008; Larson, Doran et al. 2009).

Leaving this aside, as expressed before, Bach denies that we usually have intuitive access to what is said and, consequently, he emphasizes that we should not rely on speaker-hearers' intuitions to build our semantic theories. The main objection to this is that Bach fails to be a consistent proponent of this strategy and, although he asks us not to take intuitions too seriously, he ultimately ties his notion of what is said to speaker-hearers' intuitions. ${ }^{5}$

We should remember that Bach's what is said corresponds to the locutionary act, i.e. what is minimally and literally uttered. To attend to what is literally uttered is not to rely on people's intuitions; it is simply to use utterances as data from a third point of view. This use of linguistic data does not imply relying on intuitions; it just involves observing certain behavior. What do I mean by this? Bach is not relying on the reports of subjects about what they take themselves to experience as what is said, or what they say they experience as what is said; he is just attending to the physical elements present in a linguistic event. This is equivalent to saying that neurologists use the behavior of patients with visual neglect as data, though they do not take into account the patients' intuitions about what they take themselves to be doing or seeing. In no way is Bach relying on speaker-hearers' opinions about the content of what is said; he is relying on their linguistic production. In other words, he is just attending to the linguistic behavior without paying attention to the intuitions.

Of course, to show that there is a structure that corresponds to this minimal notion of what is said still does not show that it actually plays a role in our communicative practices, and thus, that it is an important and useful theoretical notion when describing the processing of linguistic information. This has been one of the main objections advanced by Robyn Carston. Bach's what is said seems to be redundant when it comes to offering a cognitive processing story about our understanding of linguistic events.

According to relevance theorists like Carston, "the very minimal semantic information encoded in the utterance provides the linguistic basis for the pragmatic system to work on, without any need for a level of what is said" (2002, p.174). Carston believes that the processes involved in recovering what is communicated proceed directly from a decoded logical form present in the utterance. Then, Bach should still 
offer reasons why his notion of what is said is the right way to carve up communicative phenomena.

My answer to this criticism is that the theoretical import of Bach's what is said and its psychological relevance will ultimately rely on psychological evidence. And recent evidence suggests that Bach's minimal notion of what is said is (in most circumstances) an inaccessible structure that does play a role in the processing of language production and comprehension.

Before presenting this evidence, I want to state a general point regarding the nature and aim of semantic theories. The analysis offered by scholars like Bach, Recanati, and the relevant theorists has empirical consequences if we think that a position that tells us how to carve up communicated content entails certain stages in the processing of utterances. Thus, when evaluating Bach's proposal, the question at stake is whether we should postulate a stage in linguistic processing in which a minimal (sub)proposition corresponding to the uttered structure is used to make relevant (subliminal) inferences in communicative events.

As claimed, the minimalist story is empirically grounded. In a series of experiments designed by Bezuidenhout and Cutting (2002), subjects were presented with sentences and two different types of story-contexts for each sentence. One storycontext was biased towards an enriched interpretation of the sentence, and the other was biased towards a minimal interpretation of the target sentence. The stories were presented on a computer screen one line at a time. At the end, a mask of X's appeared on the screen, followed by a sentence in capital letters. Participants were asked to judge whether the sentence in capital letters exactly matched, word for word, the last sentence of the story (the target sentence). In some cases the sentence presented was a minimal paraphrase of the target sentence which expressed what is strictly and literally said by the sentence, while in other cases it was an enriched paraphrase which better expressed what was meant by the target sentence. The measurement of interest was the time it took for people to read the final sentence in the stories. Different models would make different predictions about the time that it would take to read target sentences in enriched vs. minimal contexts. The results showed that sentence reading was slower in minimal as opposed to enriched contexts. These results would indicate that in all contexts both the minimal (Bach's what is said) and the enriched interpretation (impliciture) are processed, but the enriched interpretation is usually more accessible. Thus, in contexts that support the literal interpretation, that interpretation must compete with and override the enriched interpretation, slowing down the reading times.

Needless to say, this evidence is not conclusive, but it illuminates the way in which the presence and processing of what is said (which ordinarily lacks intuitive accessibility) can be tested and assessed empirically.

Principia 21(1): 141-153 (2017). 


\section{Conclusion}

I have defended the view that Bach's tripartite distinction between what is said, implicitures, and implicatures offers a theoretically and empirically viable option that can respond to the classical problems faced by Grice's notion of what is said and what is implicated, by setting new boundaries to the semantic/pragmatic distinction. This strategy consists in abandoning the entailment from what is said to what is meant, and defending a semantic notion of what is said that departs from speaker-hearers' intuitions. This proposal has important consequences regarding the evidence that should be used by philosophers of language when evaluating their semantic theories. Furthermore, it has consequences concerning the right way to carve up linguistic processing.

In general terms, my aim was to defend the plausibility of moderate semantic minimalism as a viable form of neo-griceanism that claims that semantic content is not speech act's content, and considers that the object of semantics is minimally infiltrated by context. This view entails that semantic content is not primarily consciously accessible and that our semantic theories should not pretend to specify consciouslevel content. We should, instead, understand semantic theories as accounts of the tacit structures and processing strategies that underlie and make possible communicative events. Thus, the defender of minimalism considers that speakers' intuitions are orthogonal to semantic theorizing. Speaker-hearers' intuitions might be relevant when offering an account of pragmatic content; but here, again, the processing underlying communication could plausibly turn out to be a series of subpersonal, unconscious inferences that determine speaker's meaning. These unconscious inferences could be based on subpersonal "gricean-like" calculations concerning the expectations and intentions of the parties involved in the communicative event, which could determine speaker's meaning without the speaker-hearer being aware of the constitutive role played by intentions. Ultimately, this has to be assessed empirically.

\section{Acknowledgments}

Thanks to Jodie Azzouni and members of the 2011 seminar on the phenomenology of public language at Tufts University for the helpful discussions and comments on earlier versions of this paper. Thank you also to an anonymous reviewer for the insightful comments.

\section{References}

Azzouni, J. 2013. Semantic Perception: How the Illusion of a Common Language Arises and Persists. Oxford: Oxford University Press.

Austin, J. L. 1962. How To Do Things With Words. 2nd Edition, ed. J.O. Urmson and M. Sbisá. Cambridge, MA: Harvard University Press.

Principia 21(1): 141-153 (2017). 
Bach, K. 1994. Conversational impliciture. Mind and Language 9: 124-162.

- 2001. You Don't Say? Synthese 128: 15-44.

. 2006. The Excluded Middle: Semantic Minimalism without Minimal Propositions. Philosophy and Phenomenological Research 73(2): 435-442.

Bezuidenhout, A.; Cutting, J. C. 2002. Literal meaning, minimal propositions and pragmatic processing. Journal of Pragmatics 34: 433-356.

Borg, E. 2004. Minimal Semantics. Oxford University Press: Oxford.

Cappelen, H.; Lepore, E. 2005. Insensitive Semantics: A Defense of Semantic Minimalism and Speech Act Pluralism. Blackwell: Oxford.

Carston, R. 2002. Thoughts and Utterances: The Pragmatics of Explicit Communication. Blackwell: Oxford.

Frith, U.; Happé, F. 1994. Autism: beyond "theory of mind". Cognition 50: 115-132.

García-Carpintero, M. 2001. Gricean Rational Reconstructions and the Semantics/Pragmatics Distinction. Synthese 128: 93-131.

- 2006. Recanati on the Semantics/pragmatics Distinction (Recanati sobre la distinción entre semántica y pragmática). Crítica: Revista Hispanoamericana de Filosofía 38(112): $35-68$.

Grice, H. P. 1957. Meaning. The Philosophical Review 66(3): 377-388.

- 1989. Studies in the Way of Words. Cambridge: Harvard University Press.

Hansen, M. B. 2008. On the availability of "literal" meaning: evidence from courtroom interaction. Journal of pragmatics 40(8): 1392-1410.

Kaplan, D. 1989. Demonstratives. In: J. Almog; J. Perry; H. Wettstein (eds.) Themes from Kaplan. Oxford: Oxford University Press.

Larson, Meredith; Doran, Ryan et al. 2009. Distinguishing the Said from the Implicated Using a Novel Experimental Paradigm. In: Uli Sauerland und Kazuko Yatsushiro (Hg.): Semantics and Pragmatics. From Experiment to Theory. Basingstoke: Palgrave Macmillan, pp.74-93.

Leslie, A. M.; Thaiss, L. 1992. Domain specificity in conceptual development: Neuropsychological evidence from autism. Cognition 43: 225-251.

Levinson, S. 2000. Presumptive Meanings: The Theory of Generalized Conversational Implicature. MIT Press.

Malle, B. F. 2002. The relation between language and theory of mind in development and evolution. [website]

Prinz, J. 2011. The sensory basis of cognitive phenomenology. In: T. Bayne; M. Montague (eds.) Cognitive Phenomenology. Oxford: Oxford University Press.

Recanati, F. 2001. What is said. Synthese 128: 75-91.

- 2004. Literal Meaning. Cambridge: Cambridge University Press.

Scholl, B. J.; Leslie, A. M. 1999. Modularity, development, and 'theory of mind'. Mind and Language 14: 131-153.

Soames, S. 2002. Beyond Rigidity. Oxford University Press: Oxford.

Sperber, D.; Wilson D. 2002. Pragmatics, Modularity, and Mind-Reading. Mind and Language 17: 3-23.

Villier, J. 2007. The interface between language and theory of mind. Lingua 117(11): 18591878.

Wilson, D.; Sperber, D. 1986: Pragmatics and modularity. In: Chicago Linguistic Society Parasession on Pragmatics and Grammatical Theory 22: 67-84. Reprinted in S. Davis (ed.)

Principia 21(1): 141-153 (2017). 
1991: Pragmatics: A Reader. Oxford: Oxford University Press.

\author{
PATRICIA MARECHAL \\ Harvard University \\ marechal@fas.harvard.edu
}

\title{
Notes
}

${ }^{1}$ By the phenomenological experience of public language I refer to "what we are capable of recognizing ourselves as conscious of, and speaking about, in this domain" (Azzouni 2013, p.19). It is important to notice that the notion of phenomenology in place here is an "expansionist" one. The debate between "expansionist" and "restrictive" theories of phenomenology would take us far from the purpose of this paper, but I want to point out that many scholars working in philosophy of mind and psychology would deny the existence of a phenomenological experience of the meaning of utterances (see Prinz 2011 for a review of this debate). An expansionist proposal of cognitive phenomenology should be defended against "restrictivism", a view that has important empirical support.

2 Bach has been misclassified as a moderate contextualist by Cappelen and Lepore (2005). He explicitly presents himself as a "minimalist" (Bach 2006). Clearly, his proposal is a form of moderate minimalism as will become evident in the following sections of this paper.

${ }^{3}$ Bach calls an arrangement of sentence constituents "a 'propositional radical' to indicate that, although it comprises the entire semantic content of the sentence, it lacks at least one constituent needed for it to be true or false and to be the content of a thought or a statement" (2006, p.436).

${ }^{4}$ Interestingly, the development of linguistic performance seems to be tightly connected with mind-reading capacities. Psychologists have argued that there is a connection between language and theory of mind abilities: in normal development, the onset of communicative skills and mind-reading abilities seems to overlap (Malle 2002; Villiers 2007). This would explain why autistic individuals (typically considered to have a deficit in theory of mind) usually exhibit severe deficits in communication. It is important to mention that a low percentage of autistic people do exhibit linguistic abilities despite failing at theory of mind tests, such as the false-belief task; however, most of the autistic individuals that develop basic language understanding still show severely deteriorated communicative skills and cannot engage in adequate linguistic exchanges, while others eventually succeed in theory of mind tests when framed in ways that are not so demanding in terms of executive functions.

${ }^{5}$ This objection refers to Bach's use of the Indirect Quotation (IQ) test, which has been subject to serious criticism (Carston 2002) and has led Bach to eventually abandon it. As I said in the introduction, my primary aim is to work out a plausible account of a minimalist theory using Bach's proposal as a template. Consequently, I will not address the non-viability of the IQ test.

Principia 21(1): 141-153 (2017). 